\title{
Umbilical Endometriosis: A potential encounter for general surgeons
}

Samantha S Mooney ${ }^{1}$ (MBBS(Hons), MRepMed), and Lenore Ellett ${ }^{1}$ (MBBS(Hons), FRANZCOG)

1. Mercy Hospital for Women, Department of Endosurgery

Figures: 3 (submitted as separate documents)

Figure 1: Umbilical lesion with enlargement \& bleeding at time of menses

Figure 2: a) ultrasound image in transverse plain indicating $\sim 15 \mathrm{~mm}$ lesion; b) Doppler ultrasound indicating minimal peripheral vascularity; c) computer tomography (CT) excluding hernia sac (arrow)

Figure 3: 6 weeks following umbilical excision

Word Count: 748

Corresponding Author Details:

Dr Samantha Mooney

Mercy Hospital for Women

163 Studley Road, Heidelberg VIC 3084

0402923861

samantha.mooney39@gmail.com

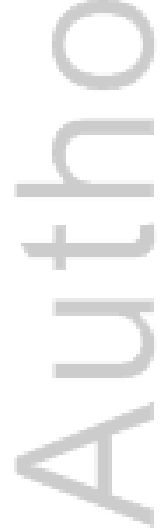

This is the author manuscript accepted for publication and has undergone full peer review but has not been through the copyediting, typesetting, pagination and proofreading process, which may lead to differences between this version and the Version of Record. Please cite this article as doi: $10.1111 /$ ans.14118

This article is protected by copyright. All rights reserved. 
A 29year-old female was reviewed in the general surgery outpatient department and referred to the gynaecology clinic at the attached tertiary institution. She reported an umbilical lump, which would enlarge and bleed with her menses (Figure 1). She had concurrent dysmenorrhea, menorrhagia and dyschezia. The patient had undergone excisional biopsy of the umbilical lesion under local anaesthetic in Chile in 2013, but noted gradual recurrence and worsening of symptoms on cessation of the combined oral contraceptive pill 2 years prior to review. She reported an (open) appendicectomy at age 6years.

Physical examination demonstrated a tender $10 \times 15 \mathrm{~mm}$ nodule at the umbilicus. Pelvic and abdominal wall ultrasounds showed a normal pelvis; a lesion at the umbilicus $(\sim 15 \mathrm{~mm}$ diameter, see Figure 2), with mild hypervascularity at the border was reported. CT abdomen/pelvis confirmed the ultrasound findings of an umbilical nodule and absence of a hernia.

The woman underwent an operative laparoscopy with Palmer's point entry ${ }^{1}$ and establishment of pneumoperitoneum. There were no umbilical adhesions. A $5 \mathrm{~mm}$ port was inserted cephalad to the umbilical lesion under laparoscopic vision. Extensive peritoneal endometriosis was noted and excised bilaterally over the pelvic side-walls, uterosacral ligaments and para-rectal spaces. Chromotubation proved patent tubes. The uterine cavity was unremarkable on hysteroscopy and a levonorgestrel intrauterine device (IUD) 52mg (Mirena ${ }^{\circledR}$; Bayer, Germany) was inserted for symptom control and contraception. The umbilical nodule was excised with sharp dissection. The rectus sheath defect $(15 \mathrm{~mm})$ was closed with PDS under laparoscopic vision from Palmer's point. The patient was discharged home 12 hours later. On review 6weeks post-operatively, the umbilicus was well-healed with no evidence of recurrence (Figure 3). 
Endometriosis is diagnosed in $5-10 \%$ of women of reproductive age ${ }^{2}$. It is responsible for pain syndromes - acute and chronic - anatomical distortion and infertility. Endometriosis is defined as the presence of endometrial tissue beyond the uterine cavity ${ }^{3}$ (Vercellini, 2014). Endometriosis most commonly involves the pelvic organs (ovaries, fallopian tubes, recto-vaginal pouch, uterosacral ligaments and pelvic peritoneum) but has also been described in other organs and tissues. Umbilical endometriosis (UE) affects less than $1 \%$ of women with endometriosis ${ }^{4}$. Indeed, its rarity was highlighted by Victory et $\mathrm{al}^{5}$ (2007) who reported only 122 cases in the English literature between 1966 - 2007.

In its 'secondary' form, UE is a type of cutaneous endometriosis occurring due to direct seeding of endometrial tissue into cutaneous scars at the time of pelvic surgery. 'Primary' UE occurs in the absence of such pelvic surgery ${ }^{6}$. Multiple theories exist to explain the pathophysiology of primary umbilical endometriosis: "embryonal rest theory" or mullerianosis, lymphatic dissemination, or transplantation and implantation of endometrial tissue from retrograde menstruation $^{3,7}$ (E in S et al, 2016; Burney \& Guidice, 2012). In the aforementioned case, the prior open appendicectomy significantly pre-dated menarche and did not involve an umbilical incision, thus this patient likely represents another case of primary umbilical endometriosis.

Our patient presented with the pathognomonic history and clinical findings of UE, or Villar's nodule $^{5}$ (Victory et al, 2007), named after the initial reporting physician. In the literature review by Victory et $\mathrm{al}^{5}$ (2007) women typically presented with a tender, painful and non-reducible umbilical mass. Average lesion size was $2.3(+/-0.2 \mathrm{~cm})$ diameter, almost 50\% reported cyclical 
bleeding, and 90\% cyclical swelling. The majority (73.1\%) denied history of endometriosis, and less than $5 \%$ had a past history of umbilical laparoscopic trochar insertion. Our patient's gynaecological history also suggested pelvic endometriosis, characterized by dymenorrhoea and dyschezia.

Previous authors have reported some difficulty in diagnosing primary $\mathrm{UE}^{8}$; the sensitivity and specificity of ultrasonography, computerized tomography and magnetic resonance imaging are low and no techniques describe pathognomonic findings ${ }^{9}$. In this patient's case, imaging assisted in providing information regarding the size of the nodule and exclusion of hernia.

Due to the rarity of UE, no guidelines exist for its treatment. Most authors agree that surgery is indicated, with local excision of the nodule or removal of the entire umbilicus being the most common options, with or without laparoscopy to diagnose and treat pelvic endometriosis ${ }^{4,5}$. Medical therapy has been described in a handful of cases, with mixed results. In the described clinical case, the size of the lesion, its recurrence despite prior surgical excision, as well as her troubling pelvic pain symptoms were indications for surgical therapy. Insertion of the Mirena IUD was recommended for menstrual suppression, symptom control and prevention of further pelvic endometriosis. Total removal of the umbilicus was chosen as the preferred operation in an attempt to avoid further local recurrence ${ }^{10}$.

UE is a rare condition that must be considered in the differential diagnosis of umbilical lesions. 


\section{References:}

1. Palmer (Palmer, 1974)

2. Bush D, Evans S, Vancaillie T. (2011) The \$6 Billion Woman and the \$600 Million GirlThe Pelvic Pain report. Accessed 27/12/16 from

http://www.painaustralia.org.au/images/pain_australia/News/Pelvic_Pain_Report_RFS.p df

3. Vercellini P, et al (2014). Endometriosis: pathogenesis and treatment. Nat Rev Endocrinol.;10(5):261-75.

4. E in S, et al (2016). Primary umbilical endometriosis: A painful swelling in the umbilicus concomitantly with menstruation. Int J Surg Case Rep. 2016; 28: 78-80.

5. Victory R, et al (2007). Villar's nodule: a case report and systematic literature review of endometriosis externa of the umbilicus. J Minim Invasive Gynecol.;14(1):23-32.

This article is protected by copyright. All rights reserved. 
6. Boesgaard-Kjer D, et al (2016). Primary umbilical endometriosis (PUE). Eur J Obstet Gynecol Reprod Biol. pii: S0301-2115(16)30244-5. doi: 10.1016/j.ejogrb.2016.05.030. [Epub ahead of print]

7. Burney RO, Giudice LC (2012). Pathogenesis and pathophysiology of endometriosis. Fertil Steril.;98(3):511-9.

8. Theunissen C, and Ijmpa F. (2015) Primary umbilical endometriosis: a cause of a painful $=$ umbilical nodule. J Surg Case Rep. (3): rjv025.

9. Savelli L, et al (2012). Endometriosis of the abdominal wall: ultrasonographic and Doppler characteristics. Ultrasound Obstet. Gynecol. 39:336-340.

10. Pramanik SR, et al (2014). Primary umbilical endometriosis: A rarity. J Hum Reprod Sci.; 7(4): 269-271.

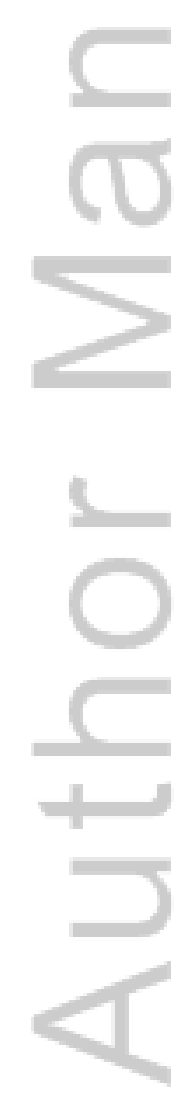

This article is protected by copyright. All rights reserved. 


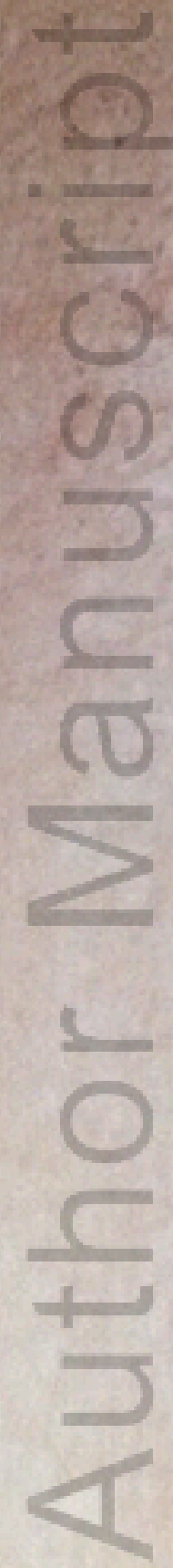

Figure S1 - ClinicalPhoto, Pre-excision.tif

This article is protected by copyright. All rights reserved. 


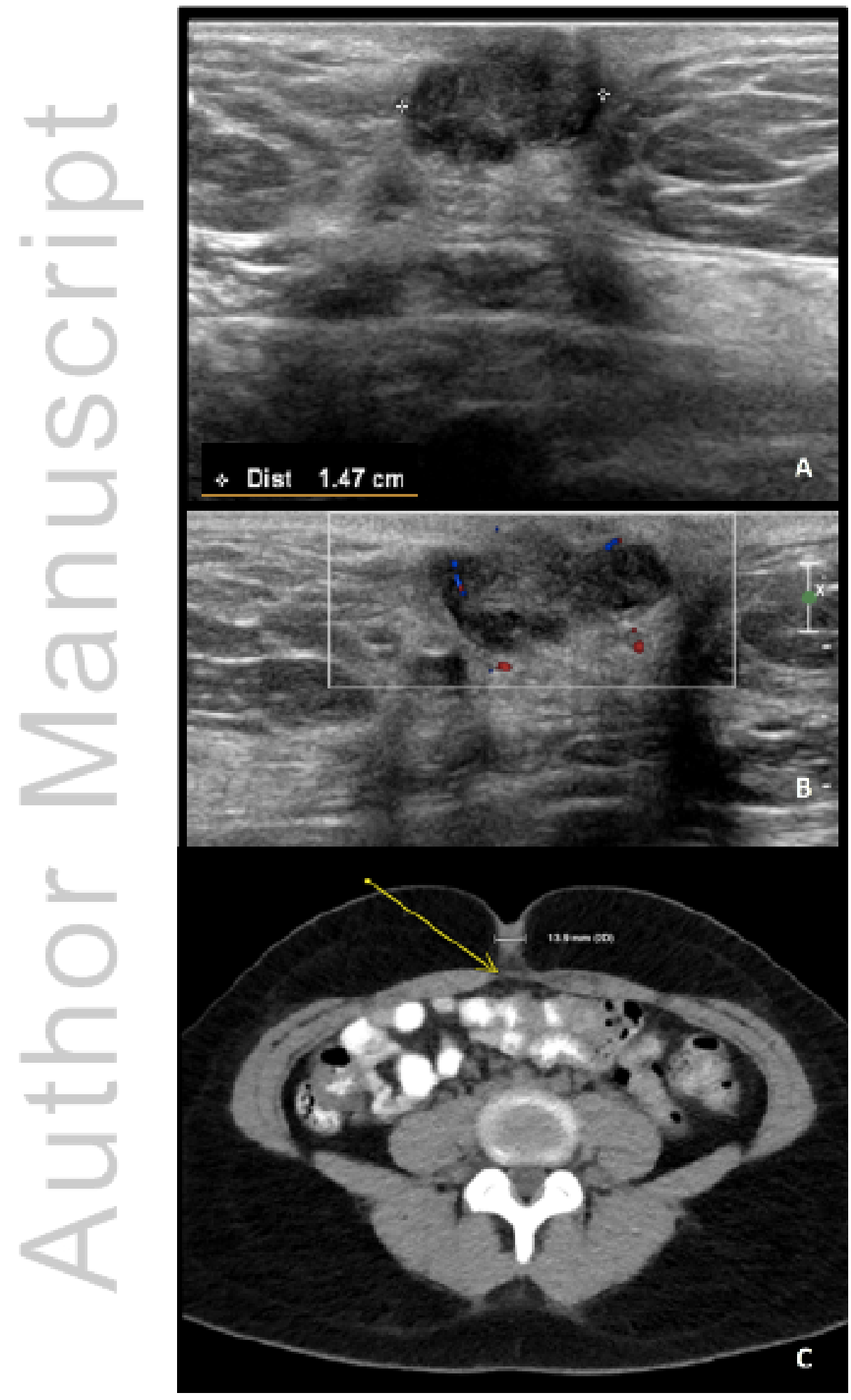

Figure S2- Radiology Images.tif 


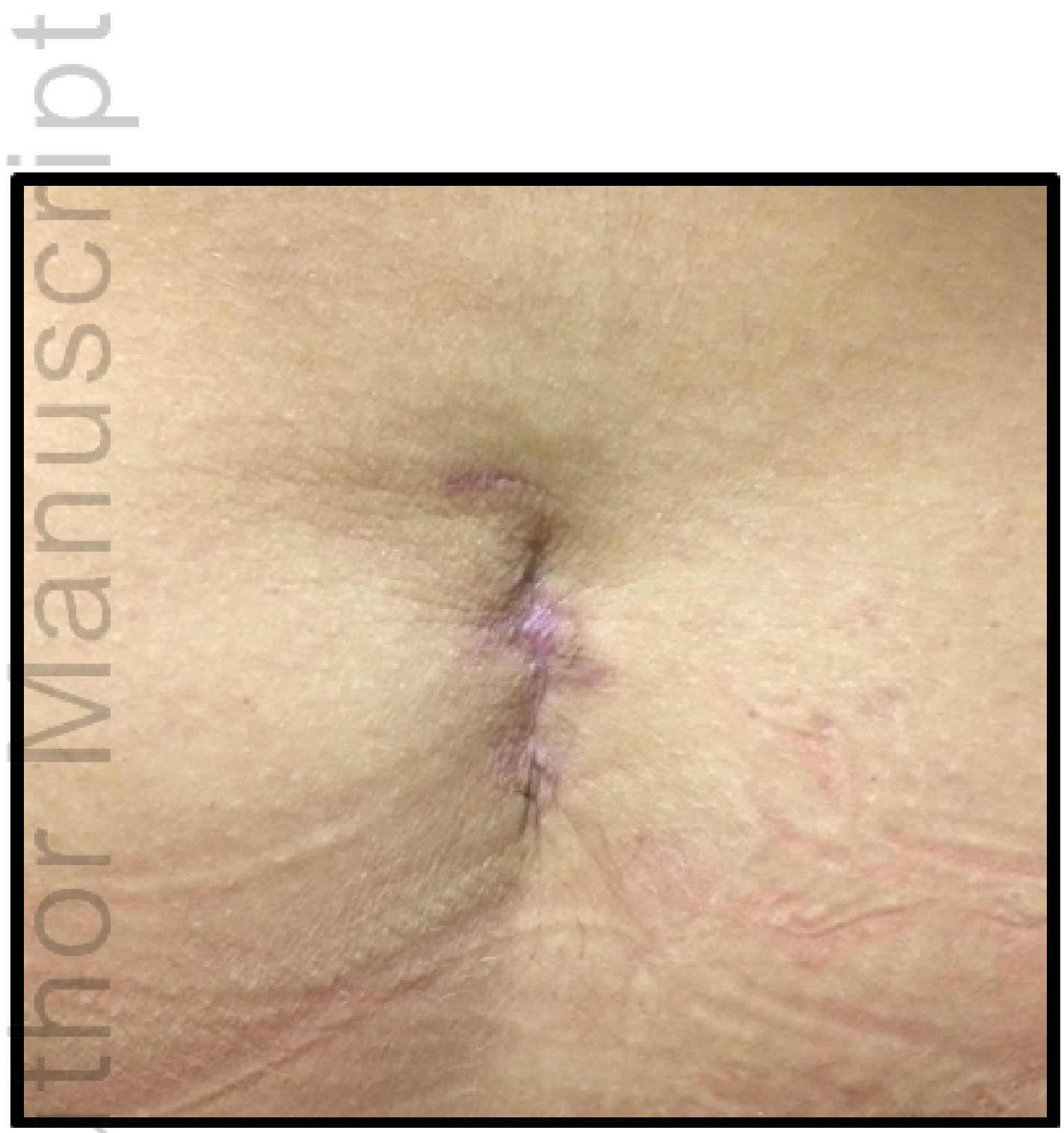

Figure S3- Clinical Images, post-excision.tif

This article is protected by copyright. All rights reserved. 


\section{University Library}

\section{- M M I N E R VA A gateway to Melbourne's research publications}

Minerva Access is the Institutional Repository of The University of Melbourne

Author/s:

Mooney, SS;Ellett, L

Title:

Umbilical endometriosis: a potential encounter for general surgeons.

Date:

2019-04

Citation:

Mooney, S. S. \& Ellett, L. (2019). Umbilical endometriosis: a potential encounter for general surgeons.. ANZ J Surg, 89 (4), pp.440-442. https://doi.org/10.1111/ans.14118.

Persistent Link:

http://hdl.handle.net/11343/293275 